\title{
FIBROMIALGIA: UMA HISTERIA CONTEMPORÂNEA
}

\author{
Maria Amélia de Carvalho Bezerra ${ }^{1}$ \\ Allyne Evellyn Freitas Gomes ${ }^{2}$
}

RESUMO: Este artigo aborda a doença da Síndrome da Fibromialgia (FM) como uma forma de histeria contemporânea, realizando um comparativo entre o quadro clínico da FM e das manifestações histéricas sob a ótica psicanalítica. A fibromialgia se apresenta por meio de dores crônicas, em no mínimo ir partes do corpo de 18 estabelecidas para o diagnóstico pelo período de 3 meses ou mais, com ausência de causas orgânicas identificadas. Sua maior incidência ocorre em mulheres adultas dos 35 aos 44 anos de idade, porém existem casos em crianças, idosos e homens. A confirmação do diagnóstico é de difícil confirmação devido seu caráter subjetivo por não existir exames clínicos que corroborem o resultado das queixas dolorosas. Objetivamos explanar sobre a enfermidade utilizando o modelo médico, conceituar a histeria conforme descrito por Sigmund Freud no século XIX em relação a sua sintomatologia e causalidade, evidenciando a importância da psicanálise no tratamento para diminuição dos sintomas. $O$ estudo, apresenta um levantamento de publicações cientificas que abordam a fibromialgia a luz da psicanálise, por meio de uma revisão de literatura. Desse modo foram realizadas pesquisas nas bases de dados Scielo-Brasil, Pepsic e na literatura das obras Freudianas. Nesse contexto concluímos que os sintomas apresentados na Síndrome da Fibromialgia se assemelham ao quadro clínico da histeria contribuindo assim para uma melhor compreensão desta síndrome e assim auxiliando no seu tratamento.

Palavras-chave: Histeria. Fibromialgia. Psicologia. Psicanálise.

\section{INTRODUÇÃO}

A Síndrome da Fibromialgia é assim considerada pela diversidade de sintomas apresentados, mas expressivamente, pela dor crônica em determinadas partes do corpo sem causas orgânicas aparentes.

Ainda hoje, em 2021, apesar dos avanços da medicina, a Síndrome da Fibromialgia se apresenta com difícil diagnóstico e tratamento para a classe médica devido sua condição sintomatológica sem causas orgânicas. Neste cenário a aproximação do quadro clínico desta síndrome com a histeria proporciona uma melhor compreensão da situação do paciente, ressaltando a importância de estudos mais aprofundados sobre a temática.

\footnotetext{
${ }^{\text {I }}$ Acadêmica do Curso de Psicologia do Centro Universitário Mauricio de Nassau.

2 Psicóloga, Mestre em psicologia Universidade Federal de Pernambuco, Docente do Centro Universitário Mauricio de Nassau. 
$\mathrm{Na}$ histeria, conceito bastante estudado e difundido por Freud na elaboração da psicanálise, bem como, na fibromialgia, a sintomatologia se mostra em alguns aspectos de forma similar, principalmente, ao que se refere a inexistência de uma causa orgânica para apresentação da dor crônica e sua maior predominância em mulheres.

A psicoterapia revela-se, neste contexto, como um suporte muito importante para o tratamento da enfermidade junto a medicações específicas. Ao trabalhar os aspectos psíquicos que interferem diretamente no quadro doloroso da fibromialgia, proporcionando um lugar de fala para o sujeito efetuar sua catarse, o mesmo irá trabalhar suas questões emocionais e com isso, como observado em muitos casos, diminuir os sintomas dolorosos que tanto interfere no dia a dia do sujeito.

Estudar este tema e entender suas causas para desenvolver tratamentos contra esta enfermidade, se faz cada vez mais necessário, pois a Síndrome da Fibromialgia é uma doença que debilita o sujeito interferindo significativamente em sua vida, além do grande aumento no número de casos descobertos nos últimos anos.

A partir da falta de mais estudos sobre a fibromialgia, fica evidente a necessidade no aumento do número de pesquisas sobre o tema, como por exemplo, suas possíveis causas e 1510 fatores gatilhos para início da doença. O objetivo deste trabalho é suscitar o aumento das pesquisas sobre a doença, bem como esclarecer baseando-se nos pressupostos da teoria psicanalítica, a luz da teoria Freudiana, no que concerne ao estudo e tratamento da Histeria, estimular o desenvolvimento na criação de uma prática do cuidado mais eficiente, devolvendo aos pacientes uma melhor condição de vida, por meio da psicoterapia de base psicanalítica pela associação livre, que vem demonstrando sucesso no tratamento de pacientes com Fibromialgia.

\section{MÉTODO}

O método de pesquisa realizado neste trabalho é de natureza qualitativa, alicerçando-se na pesquisa bibliográfica como técnica de coleta de dados de cunho analítico e interdisciplinar, nas dependências do Centro Universitário Maurício de Nassau, campus Graças, na cidade de Recife, no estado de Pernambuco, e por meio de pesquisas on-line. 
O início da pesquisa ocorreu no mês de março no ano eletivo de 2020 e se estenderá até outubro com a redação do artigo.

A população deste estudo foi constituída pela literatura pertinente ao tema estudado por meio da coleta de dados em obras publicadas pelo autor de referência da Psicanálise, Sigmund Freud, além de literatura relacionada a Fibromialgia e Histeria, indexadas nos bancos de dados das plataformas Scientific Eletronic Library Online (SCIELO), Google Acadêmico e Periódicos Eletrônicos de Psicologia (PePSIC).

Os critérios utilizados para inclusão das referências bibliográficas contemplam as literaturas no idioma português e publicadas nas bases de dados citadas no tamanho da amostra. Empregando os seguintes descritores para busca bibliográfica: Fibromialgia, Histeria, Psicanálise e Psicossomática. Além da literatura das obras Freudianas. Para este trabalho foram desconsiderados artigos publicados antes de 2006, com exceção de um artigo considerado relevante para a pesquisa, e revistas com classificação superior a B2 para psicologia na Plataforma Sucupira.

Após a leitura crítica da literatura acerca do tema, a análise dos dados da pesquisa foi realizada a separação dos tópicos considerados relevantes que supostamente responderiam as 1511 questões da pesquisa.

Os aspectos éticos por se tratar de uma revisão bibliográfica, não será submetido à avaliação do Comitê de Ética e Pesquisa do Centro Universitário Maurício de Nassau e de acordo com a Resolução 466/2012 do Conselho Nacional de Saúde (CNS). E não oferece riscos a população, porém seus benefícios em divulgar estudos sobre uma doença que se estuda há pouco tempo e de cunho subjetivo são muito importantes no entendimento das formas de cuidado que poderão ser despendidas aos pacientes da Síndrome da Fibromialgia.

Contudo o artigo apresentado respeita todos os preceitos éticos estabelecidos no que se refere a prezar pela legitimidade das informações, referenciando e citando todos os autores dos trabalhos utilizados, e o respeito à dignidade humana na publicação dos dados coletados.

\section{I.I O que é a fibromialgia}

A denominação fibromialgia, palavra derivada do latim fibro (tecido fibroso, presente em ligamentos, tendões e fáscias), e do grego mio (tecido muscular), algos (dor) e ia 
(condição), foi proposta inicialmente por Yunus e cols. em I98I, com o intuito de substituir o termo fibrosite, até então utilizado para denominar um tipo particular de reumatismo caracterizado pela presença de pontos endurados musculares dolorosos à palpação, a partir do entendimento de que não havia, nestes adoecimentos, inflamação tecidual. (HELFENSTEIN JUNIOR; GOLDENFUN; SIENA, 2012).

Os autores acrescentam, ainda, que só em 1990, um comitê do Colégio Americano de Reumatologia (ACR) definiu como critérios classificatórios da FM a presença na história clínica de dor generalizada, afetando o esqueleto axial e periférico, acima e abaixo da cintura, com duração superior a três meses; e do exame físico com dor à palpação com força aplicada de $4 \mathrm{~kg} / \mathrm{cm}^{2}$ em pelo menos II dos seguintes 18 tender points (9 pares ver figura I). Helfenstein Junior, Goldenfun e Siena (2012, p. 359) esclarecem que atualmente os critérios diagnósticos atuais não contemplam os tender points, entretanto, englobam os sintomas não relacionados ao aparelho locomotor. Além da dor musculoesquelética, avaliam a gravidade da síndrome e são mais úteis para estabelecer o diagnóstico.

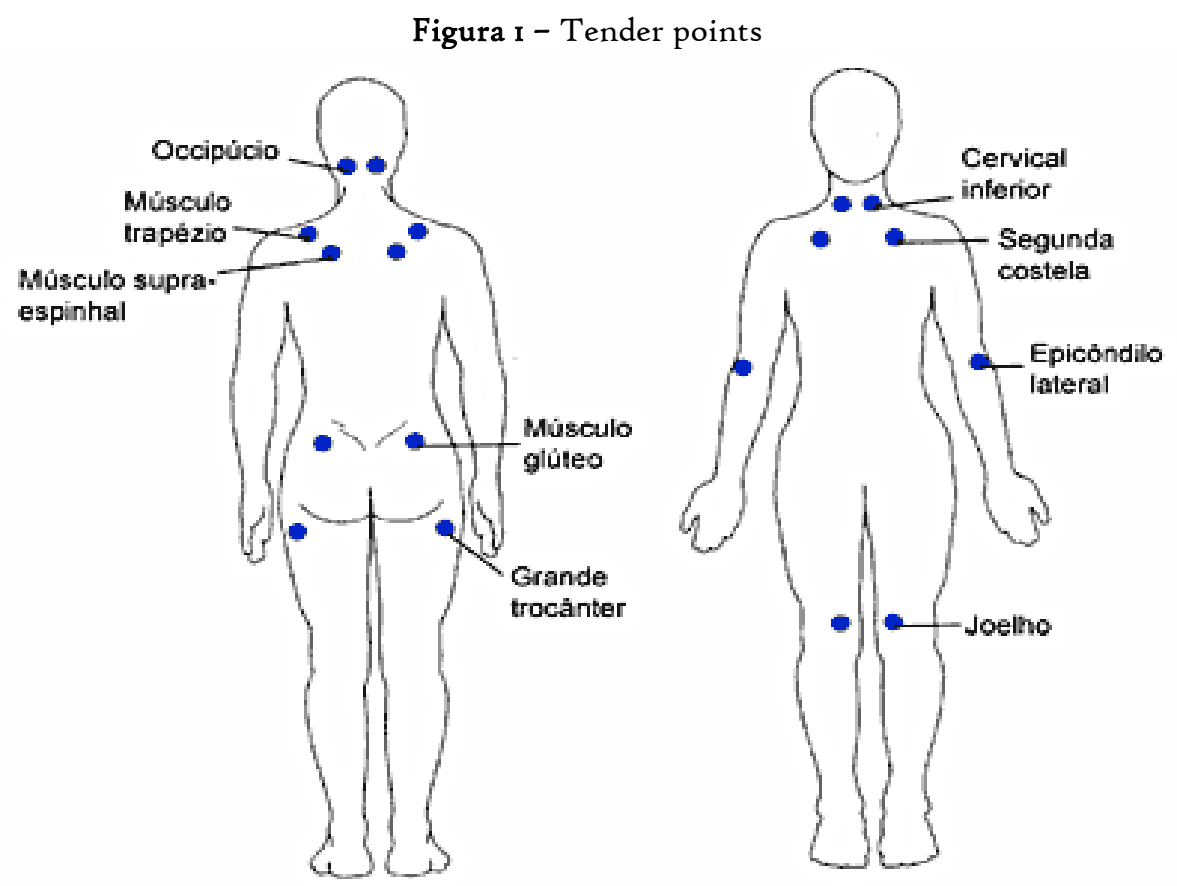

Fonte: Site Abrafibro³ - Associação Brasileira dos Fibromiálgicos

\footnotetext{
3 Disponível em: https://www.abrafibro.com/2014/o2/fibromialgia-e-uma-doenca-comum.html. Acesso em: 26 mar. 2020.
} 
Estudos mais recentes apontam que a origem dos sintomas parece ser devida às alterações do Sistema Nervoso Central (SNC), em especial dos mecanismos de percepção e modulação da dor, tendo como causa o desequilíbrio de substâncias analgésicas do cérebro (serotonina) e as substâncias que promovem a dor (substância P) (KOTAKA,2017, p. 201). Estas alterações percebidas servem como um ponto de partida para um tratamento mais assertivo e direcionado.

No Brasil, os dados, mais recentes, e que servem de base a estudos médicos, referem-se a levantamento realizado na cidade de Montes Claros, Minas Gerais. (..) A prevalência observada na população é de 2,5\%, a maioria sendo do sexo feminino, das quais 40,8\% com 35 a 44 anos de idade. (SENNA et.al, 2004 apud BESSET et.al., 2010, p. 1249).

O caráter eminentemente subjetivo dos transtornos ligados à fibromialgia (dor, fadiga, mal-estar, transtornos do sono) sugere a adequação de uma avaliação e de uma terapêutica de tipo multidisciplinar. Com efeito, quaisquer que sejam as modalidades de tratamento escolhidas, os elementos psíquicos não podem ser negligenciados por muito tempo. (BESSET et. al., 2010, p. 125I).

Para Kotaka (2017, p. 205) a síndrome ocorre após algum fato traumático marcante ou de fatos traumáticos repetidos menos intenso, ou, ainda, após um quadro infeccioso. [...] os traumas podem ser devidos a causas físicas, tais como acidentes e agressões, mas podem ser1513 emocionais [...], após perda de posições ocupadas profissionalmente, [...] doenças causadas por vírus, especialmente, Hemophilus influenza, o Parvovírus, o Coxsackie B e o Epstein-Barr.

Nesse contexto, o peso dos códigos e das limitações socioculturais, mas também psicológicas, para todo paciente convidado a relatar sua experiência de dor, deveria ser levado em consideração. (BESSET et.al.,20ı, p. 1254). Se objetivamos saber o sentido do sofrimento dos nossos pacientes, bem como, o sentido de nosso próprio sofrimento, a lente da teoria freudiana é certamente uma ferramenta indispensável para desvendarmos a psicogênese da dor. (GUIMARÃES, 20II, p. 13).

\subsection{A HISTERIA PSICANALÍTICA}

Segundo Laplanche e Pontalis (I99I, p. 2II) a noção de uma doença histérica e muito antiga, visto que remonta a Hipócrates. Sua delimitação acompanhou as 
metamorfoses da história da medicina. [...] considera a histeria como uma doença psíquica bem definida, que exige uma etiologia específica. Por outro lado, procurando estabelecer o "mecanismo psíquico", ligou-se a toda uma corrente que considera a histeria uma "doença por representação". Como sabemos, o esclarecimento da etiologia psíquica da histeria e paralelo as descobertas principais da psicanalise (inconsciente, fantasia, conflito defensivo e recalque, identificação, transferência, etc.).

Designamos como traumas psíquicos as vivências que desencadearam o afeto original e cuja excitação foi depois convertida em fenômeno somático, e como sintomas histéricos de origem traumática as manifestações patológicas assim produzidas. (A designação "histeria traumática" já é dada aos fenômenos que, como consequência de ferimentos corporais - traumas em sentido estrito - constituem uma parte da "neurose traumática".)(FREUD, 1893-1895, p. 296).

Segundo Freud (1926-1929, p. 122), na dor física há um forte investimento no local dolorido do corpo, investimento esse que podemos chamar narcísico, que aumenta cada vez mais e age sobre o EU de modo, digamos, "esvaziador". O autor cita em sua obra sobre o narcisismo que o mesmo se refere a um complemento libidinal do egoísmo do instinto de auto conservação, do qual justificadamente atribuímos uma porção a cada ser vivo. [...] A libido retirada do mundo externo foi dirigido ao EU, de modo a surgir uma conduta que podemos chamar de narcisismo. (FREUD, I914-1916, p. 14-15,16).

O único fato de que há certeza é que a dor - inicialmente e por via de regra - nasce quando um estímulo que ataca na periferia rompe os dispositivos que protegem contra estímulos e passa a agir como um estímulo instintal constante, diante do qual são impotentes as ações musculares normalmente eficazes, que subtraem ao estimulo o local estimulado. (FREUD, 1926-1929, p. I21).

Leite e Pereira (2003, p. I0o) consideram a fibromialgia como um fenômeno que pode inscrever-se em uma organização de personalidade psicossomática ou histérica ${ }^{4}$. Com efeito, tudo que atinge o corpo mobiliza o campo do imaginário - fantasias, identidades e

$4 \mathrm{Na}$ personalidade psicossomática - seu sentido primordial é econômico; é uma energia libidinal que se transforma, se converte, em inervação somática. A conversão é correlativa do desligar-se da libido da representação no processo do recalcamento; a energia libidinal desligada é então "... transposta para o corporal”. (LAPLANCHE E PONTALIS, 199I). Na personalidade histérica - apresentam quadros clínicos muito variados. As duas formas sintomáticas mais bem identificadas são a histeria de conversão, em que o conflito psíquico vem simbolizar-se nos sintomas corporais mais diversos, paroxísticos (exemplo: crise emocional com teatralidade) ou mais duradouros (exemplo: anestesias, paralisias histéricas, sensação de "bola " faríngica, etc.), e a histeria de angústia, em que a angústia é fixada de modo mais ou menos estável neste ou naquele objeto exterior. (LAPLANCHE E PONTALIS, 1991). 
identificações -, mas também as modalidades de inscrição do sujeito no laço social e sua relação ao Outro (LACAN, 1978 apud BESSET, 2010, p. 1255).

A dor é um recurso, uma possibilidade de manter a unidade corporal, evitando a vivência do esfacelamento. A histérica, por meio da fantasia e do barulho que produz, protege-se da dor da ausência do objeto precocemente perdido. A fantasia liga a libido, que desligada e em excesso, poderia produzir um "furo melancólico" no psiquismo. (LEITE e PEREIRA, 2003, p. I03).

Se o afeto original não foi descarregado no reflexo normal, mas sim num "reflexo anormal”, também esse volta a ser desencadeado pela lembrança; a excitação proveniente da ideia afetiva é "convertida” num fenômeno corporal. (FREUD, I893-1895, p. 292).

Com isso Angerami-Camon (2012, p. 171), evidencia que após observações e estudos de Freud que nos casos de histeria, o que existia de fato era uma representação psíquica de uma ideia não consciente e intensamente carregada de afeto, entendendo que o trauma não seria um acontecimento externo, mas um violento desarranjo interno alojado no eu; o trauma sofrido pela criança não seria uma agressão externa real, mas o vestígio psíquico deixado pela agressão; não é a natureza do impacto que importa, mas a marca que resulta dele.

Com os estudos estabelecidos por Freud durante os anos e suas observações de pacientes, ele estabelece em sua obra de 1893-1895 (p. 290) como critério para identificação de1515 histéricos que só podemos qualificar de histéricos tais fenômenos quando surgem não como consequência de um afeto extremo (porém de fundamento objetivo), mas, de forma aparentemente espontânea, como manifestações mórbidas. Quanto a estas muitas observações, incluindo as nossas, demonstraram que se baseiam em lembranças que renovam o afeto original. Ou melhor: renovariam, se precisamente aquelas reações já não tivessem de produzido.

Entretanto, Freud (1893-1895, p. 294), complementa em sua teoria que o fenômeno histérico (reflexo anormal) não se afigura ideogênico mesmo aos doentes inteligentes e bons observadores, porque a ideia motivadora não é mais realçada de afeto, nem distinguida de outras ideias e lembranças; ele se apresenta como fenômeno puramente somático, sem raiz psicológica na aparência. $O$ que no caso da Fibromialgia pode dificultar ainda mais a identificação da doença e sua condução no tratamento psicoterápico. 
O termo histeria tem origem nos primórdios da medicina e resultou do preconceito, que vinculava as neuroses das doenças do aparelho reprodutor feminino. (SLOMPO e BERNARDINO, 2006, p. 268).

Freud (1893-1895, p. 264-266) afirma que "histéricas são todas aquelas manifestações mórbidas provocadas por ideias”. (...) considero a histeria um quadro clínico encontrado empiricamente, a partir da observação. (...) um fenômeno que é certamente uma unidade seria um componente da histeria em certas ocasiões, e em outras, não.

O mesmo ocorre com as algias histéricas, tão importantes na prática. Por certo, elas são com frequência causadas diretamente por ideias; são "alucinações de dor". Se as examinamos com maior cuidado, verificamos que não basta uma grande vivacidade da ideia para que se produzam; é necessário um estado anormal particular do aparelho receptor e condutor da dor (...). Se alucinações de dor aparecem com tal facilidade na histeria, devemos admitir uma excitabilidade anômala do aparelho receptor da dor. (FREUD, 1893-1895, p. 266-267, 268).

Quando, após o leve trauma de uma articulação, desenvolve-se gradativamente uma grave neurose articular, há nesse processo, sem dúvida, um elemento psíquico: a concentração da atenção na parte lesada, o que aumenta a excitabilidade das vias nervosas implicadas; mas dificilmente poder-se-ia dizer que a hiperalgia é determinada por ideias. (FREUD, I893-I895, p. 269).

As dores e essa maior sensibilidade para a dor sem uma causa orgânica plausível já eram estudadas há muito tempo, porém sem muito sucesso com os resultados obtidos, a medicina tradicional, ao não encontrar a causa orgânica da dor apenas marginalizavam essas pessoas da sociedade ou as submetiam a tratamentos degradantes em sanatórios, também sem muito sucesso. A partir de uma nova visão de Freud para o estudo da histeria e uma visão empática com este sofrimento que acometia muitas mulheres na época se iniciou um processo de regressão dos sintomas e muitas vezes até de cura com o avanço dos estudos.

Freud (I9I4-I9I6, p. 87) afirma que influenciados pelo estudo das psiconeuroses, que nos faz ver o significativo efeito da repressão, somos inclinados a superestimar o seu conteúdo psicológico, e esquecemos com facilidade que a repressão não impede a representante do instinto de prosseguir existindo no inconsciente, de continuar se organizando, formando derivados e estabelecendo conexões. $\mathrm{Na}$ realidade, a repressão perturba apenas a relação com 
um sistema psíquico, o do consciente. Diante do exposto vemos, que o afeto que fora reprimido como mecanismo de defesa do Ego, para não causar a sensação de desprazer por não, satisfazer o desejo libidinal encontrará por meio do sintoma chegar ao consciente.

Contudo, por tratar-se de traumas que estão recalcados no inconsciente e causam sintomas, muitas vezes, sem uma causa orgânica específica, Freud (1901-1905, p. 196), após analisar vários casos de histeria, conclui que o trauma psíquico, o conflito dos afetos e, como acrescentei em trabalhos posteriores, o abalo da esfera sexual. Tratando-se de coisas que se tornaram patogênicas pelo afã de ocultar-se, não se deve esperar que os pacientes as entreguem espontaneamente ao médico, nem satisfazer-se com o primeiro "não" contraposto à investigação.

\subsection{Uma histeria contemporânea}

$\mathrm{Na}$ prática da clínica psicanalítica, Freud (1914-1916, p. 88) enaltece o paciente a produzir tais derivados do reprimido, que devido a sua distância ou deformação podem passar pela censura do consciente. Não são outra coisa os pensamentos espontâneos que dele solicitamos, através da renúncia a todas as ideias intencionais conscientes e a toda crítica, e a partir dos quais reconstituímos uma tradução consciente da representante reprimida.

O quadro clínico apresentado pelos pacientes com fibromialgia pode revelar, que os efeitos mostrados no corpo pelos desarranjos subjetivo, devido especialmente à perdas e fracassos vivenciados ou da onipotência do sujeito. (KOTAKA, 2017, p. 221).

[...]quando a realidade se mantém intransigente, a libido sentindo-se impossibilitada de assumir outro objeto em substituição àquele que lhe havia sido recusado, seria compelida a tomar o caminho de regressão. A pulsão retomaria em sentido inverso ao ponto em se encontrava e o id buscaria a satisfação dos seus desejos em uma das organizações deixada para trás ou a um objeto anteriormente abandonado. [...] As pulsões, mesmo apresentando-se irreconhecíveis, buscam a satisfação, ressurgindo como sonhos, atos falhos ou sintomas. (KOTAKA, 2017, p. 219)

Após entrevistas realizadas por Slompo e Bernardino (2006, p. 272) constatou-se que os sintomas físicos descritos por pacientes acometidos pela fibromialgia eram geralmente os mesmos, diferenciando-se apenas de membro ou intensidade; (...) Traços recorrentes: pessoas que cuidam de tudo e todos; que se sentem responsáveis pela felicidade do outro; que sofreram 
perdas financeiras ou de saúde; situações de pai, marido violento; gravidez precoce; alcoolismo; abusos físicos, verbais.

Kotaka (2017, p. 196) corrobora com a ideia de Slompo e Bernardino ao descobrir na fala dos pacientes subsídios que permitem encontrar a origem inconsciente da dor manifestada por um corpo em sofrimento. [...] As pessoas que apresentam dificuldades em lidar com perdas, especialmente a perda do amor e de poder, além das alterações quanto à organização da vida pessoal, parecem mais propícias a desenvolver um quadro de sintomas e sinais correspondentes ao da fibromialgia.

Fernandes (2003) apud Kotaka (2017, p. 214) salientou, ainda, que fatores socioculturais, biológicos e psicológicos podem se apresentar interligados e se retroalimentarem, levando ao surgimento e à manutenção das dores crônicas. Outro aspecto, que deve ser considerado como fato importante aventado por CALDEIRA (200I) apud Kotaka (2017, p. 214), seria o de que o alcoolismo paterno parece apresentar casuística significativa, ao sugerir maior probabilidade da ocorre ocorrência do quadro de fibromialgia, mas, consideramos o fato de que, em muitos casos, há relatos de maus-tratos sofridos na infância por causa do alcoolismo paterno, trazendo decepções na história de vida do sujeito.

As questões psicológicas do sujeito acometido pela Fibromialgia se destacam pelo seu discurso onde encontramos traumas que não foram trabalhados para que não causassem sofrimento. Assim como escutamos nas pacientes diagnosticadas com a Síndrome da Fibromialgia, a dor localiza-se ao lado dos fenômenos psicossomáticos ou, retomando a classificação freudiana, ao lado das neuroses atuais. (LEITE e PEREIRA, 2003).

O corpo do histérico é um corpo representado, subjetivo, as alterações não são explicadas pelo real, objetivo, orgânico. As condições orgânicas recuam, mudam, assim como um passe de mágica, ao serem interpretadas, ao fazer o caminho de volta da simbologia do órgão a cena recalcada. [...] O corpo biológico não é afetado de fato, há uma integridade deste, o que não ocorre nas doenças psicossomáticas. [...] As manifestações que os histéricos sofrem não resultam de nenhuma causa orgânica, não obedecem a nenhuma lei da anatomia ou fisiologia. (ANGERAMI-CALMON, 2012, p. 28I).

Diante desse cenário, expressar a importância da psicoterapia psicanalítica é primordial no tratamento dos pacientes com fibromialgia, conforme enaltece Kotaka (2017, p. 222), a associação livre, uma das principais regras do tratamento analítico [...] permite o 
afloramento do inconsciente e a instalação da situação analítica. [...] o sujeito expressa as formas como lida com a 'falta-a-ser' e a sua modalização de gozo, para construir um novo significado para o seu existir.

Angerami-Calmon (2012, p. 286) declara que são urgentes estudos que permitam compreender a plasticidade dos sintomas que antes eram denominados "histeria" (e hoje recebem, principalmente, o rótulo de "somatização"), bem como investigações que proponham manejos mais adequados a essa ampla gama de pacientes, tanto por psiquiatras e psicólogos quanto pelos clínicos e pelos especialistas em aparelhos e sistemas orgânicos que podem ser sintomatizados "psicossomaticamente".

Diante do exposto e da dificuldade em encontrar uma causa específica para a Fibromialgia devemos nos atentar principalmente as técnicas ensinadas por Freud em seu texto sobre as recomendações ao médico que pratica a psicanálise com o intuito de auxiliar no tratamento do paciente: no entanto, essa técnica é bem simples. Ela rejeita qualquer expediente, como veremos, mesmo o de tomar notas, e consiste apenas em não querer notar nada em especial, e oferecer a tudo o que se ouve a mesma "atenção flutuante". (FREUD, I9III913, p. 149).

\section{CONCLUSÃO}

A Síndrome da Fibromialgia está cada vez mais presente em nosso dia a dia, por meio de divulgação de campanhas ou por conhecer uma pessoa que sofra com as dores crônicas, porém os estudos desta doença ainda são poucos, principalmente na investigação de um diagnóstico mais eficaz e eficiente, auxiliando em uma melhor qualidade de vida para o sujeito.

Apesar de algumas pessoas da área médica considerem a Fibromialgia como uma somatização ela apresenta-se com muitos componentes da antiga histeria e porque não denominar de uma histeria contemporânea fazendo uma atualização ao correlacionar a teoria psicanalítica da época a qual foi desenvolvida com a atualidade no que diz respeito à constituição social, ambiental e histórica dos sujeitos.

Este artigo teve como propósito esclarecer alguns critérios atuais para o diagnóstico da 
Síndrome da Fibromialgia e assim estimular mais estudos tanto na área da psicologia como da medicina sobre a doença, principalmente de forma multidisciplinar vendo o sujeito em seu contexto familiar, social e cultural como um ser único e atuante. E destacar como psicoterapia de cunho psicanalítico pode ser efetiva no tratamento desta doença que impossibilita muitas pessoas de realizar suas tarefas diárias por causa das dores fortes e debilitantes.

A importância para sociedade e para a psicologia em dialogar sobre a dor crônica, da síndrome da fibromialgia, além dos seus sintomas com a psicanálise e as condições de "cura" pela fala ou alívio do sintoma, se faz importante para todos e ressalta a necessidade da psicoterapia mais acessível a todos indivíduos os quais desejem se submeter ao processo.

\section{REFERÊNCIAS}

ANGERAMI-CAMON, Valdemar A., TORRES, Andre Roberto R. et.al.. Psicossomática e suas interfaces: o processo silencioso do adoecimento. São Paulo: Cengage Learning, 2012.

BESSET, Vera Lopes et. al. Um nome para a dor: fibromialgia. Revista mal-estar subjetividade, Fortaleza, vol. X, n. 4, p. 1245-1269, dez. 2010. Disponível em: https://periodicos.unifor.br/rmes/article/view/4968. Acesso em: 26 mar. 2020.

FIBROMIALGIA E OS TENDER POINTS. Abrafibro, 20i4. Disponível em:1520 https://www.abrafibro.com/2014/o2/fibromialgia-e-uma-doenca-comum.html. Acesso em: 26 mar. 2020.

FREUD, Sigmund, I856-1939. Obras completas, vol. 17: inibição, sintoma e angústia, o futuro de uma ilusão e outros textos (1926-1929) / Sigmund Freud; tradução Paulo Cesar de Souza I⿳亠口冋 ed. - São Paulo: Companhia da Letras, 2014.

Obras completas, vol. 12: introdução ao narcisismo, ensaios de metapsicologia e outros textos (1914-1916) / Sigmund Freud; tradução Paulo Cesar de Souza - ıạ ed. - São Paulo: Companhia da Letras, 2010.

. Obras completas, vol. ıo: observações psicanalíticas sobre um caso de paranoia relatado em autobiografia ("o caso Schereber"). Artigos sobre técnica e outros textos. (I9II-1913) / Sigmund Freud; tradução Paulo Cesar de Souza - I⿳a ed. - São Paulo: Companhia da Letras, 2010.

. Obras completas, vol. 6: três ensaios sobre a teoria da sexualidade, analise fragmentária de uma histeria ("O caso Dora") e outros textos (1901-1905) / Sigmund Freud; tradução Paulo Cesar de Souza - Iํㅡㄹ ed. - São Paulo: Companhia da Letras, 2016. 
Obras completas, vol. 2: estudos sobre a histeria em coautoria com Josef Breuer (18931895) / Sigmund Freud; tradução Paulo Cesar de Souza - ıํㅡ ed. - São Paulo: Companhia da Letras, 2016.

HELFENSTEIN Júnior, Milton; GOLDENFUN, Marco Aurélio; SIENA, César Augusto Fávaro. Fibromialgia: aspectos clínicos e ocupacionais. Revista da Associação Médica Brasileira, [s.l.], v. 58, n.3, p.358-365, maio 2012. Elsevier BV. Disponível em: https://www.sciencedirect.com/science/article/pii/Soro4423012705225. Acesso em 3I mar. 2020. http://dx.doi.org/10.159o/so104-42302012000300018.

KOTAKA, Elia Tie. Fibromialgia: abordagem médica, psicanalítica e psicossomática. Curitiba: Juruá, 2017.

Laplanche, Jean; Pontalis, Jean-Bertrand Lefebvre. Vocabulário da psicanálise. sob a direção de Daniel Lagache; tradução Pedro Tamen - 4⿳⺈ ed. - São Paulo: Martins Fortes, I99I.

LEITE, Adriana Campos de Cerqueira; PEREIRA, Mario Eduardo Costa. Sofrimento e dor no feminino. Fibromialgia: uma síndrome dolorosa. Psychê, São Paulo, ano VII, n. 12, p. 97I06, jul.-dez. 2003. Disponível em https://www.redalyc.org/pdf/307/30701207.pdf. Acesso em: 26 mar. 2020.

SLOMPO, Thais Krukoski Marques e Silva; BERNARDINO, Leda Mariza Fischer. Estudo comparativo entre o quadro clínico contemporâneo "fibromialgia" e o quadro clínico "histeria" descrito por Freud no século XIX. Rev. latinoam. psicopatol. fundam., São Paulo , 1521 v. 9, n. 2, p. 263-278, jun. 2006. Disponível em http://www.scielo.br/scielo.php?script=sci_arttext\&pid=S I41547142006000200263\&lng=pt\&nr $\mathrm{m}=$ iso. Acesso em: 29 mar. 2020. https://doi.org/I0.1590/1415-47142006002006 